\title{
Mário de Andrade e a Música Brasileira
}

Arnaldo Daraya Contier

\author{
1. Pião \\ "Arrasta a sáia no chão \\ Oh!; pião! \\ Rodeia, pião! \\ Rodeia, pião!"
}

Paraiba

2. Lundu

"Ha treis coisa nesse mundo Rúim para quem o féiz:

É home que joga e bebe, Mulé que erra uma veiz, Cachorro que pega bode: Coitadinho deles treis!"

Rio Grande do Norte

Mário de Andrade defendia a pesquisa do folclore como a principal fonte temática e técnica do compositor erudito preocupado com a criação de uma música nacionalista e brasileira, durante as décadas de 1920 e 30.

O projeto de Mário de Andrade explicitou-se na sua poesia "Paulicéia Desvairada", no "Prefácio Interessantíssimo" (sons e palavras). e n'A Escrava que não era Isaura (traços futuristas e nacionalistas). $O$ programa doutrinário e programático sobre a construção do discurso a respeito da nacionalização da música no Brasil foi defendido pelo autor de Macunaima nos seguintes textos: O ensaio sobre amísica brasileira; Compêndio de História da Música; Introdução à EstéticaMusical; Evolução social damúsica brasileira (1939); o texto de colorações políticas para a ópera Café; O Banquete ${ }^{1}$ - diálogos tensos vivenciados pelaspersonagens SarahLight (mecenas); Janjão (compositor 
nacionalista); Pastor Fido (jornalista); Siomara Ponga (cantora erudita presa a um repertório clássico e tradicional). e Félix de Cima (burocrata "fascista", figura típica do intelectual "incompetente" cooptado . pelo Estado Novo); artigos editados no Música, doce mísica; críticas publicadas no rodapé semanal da Folha da Manhã, sob o título de "O mundo musical" (inícios dos anos 40).

Oenaltecimento da cultura popular pelos modernistas, como ponto nodal do programa nacionalista no campo da Arte Culta, apresenta um matiz de natureza neo-romântica.

A partir dos fins do século XVIII e durante o século XIX, a cultura popular tornou-se uma temática significativa para osintelectuaisalemães, ingleses, finlandeses, húngaros, sérvios, russos, entre outros. De 1774 a 1798, J.G. Herder compilou uma série de canções populares entoadas pelos camponeses, em sua obra Volkslieder. Os italianos identificavam essas canções através da expressão canti popolari; os russos, de narodye pesni; e Mário de Andrade, Renato Almeida, Luciano Gallet, Lorenzo Fernandez, de "canções populares".

A pesquisa da cultura popular como o inconsciente coletivo da Nação aflorou nas obras dos irmãos Grimm. Num ensaio sobre o Nibelungenlied, Jakob Grimm observou que o autor desses poemas era anônimo ou desconhecido, ... como é usual em todos os poemas nacionais e assim deve ser, porque eles pertencem a todo o povo... ${ }^{2}$

Os pressupostos metodológicos e teóricos da produção musicológica, na área da pesquisa folclórica no Brasil, baseavam-se nos trabalhos dos intelectuais alemães: Curt Sachs e Hornsbostel. Em especial, nas coletas realizadas por Mário de Andrade, Renato Almeida e Oneyda Alvarenga. Os estudos destes intelectuais brasileiros sobre o bumba-meu-boi, cheganças demarujos, cantigasinfantis, fundamentavamsenos "métodos" difusionistas e evolucionistas da chamada "Escola de Berlim".

Mário de Andrade, na qualidade de diretor do Departamento Municipal de Cultura de São Paulo, iniciou a pesquisa "científica" do folclore noBrasil, conforme declarações deRenato Almeida ${ }^{3}$.Patrocinou a ida de uma missão de pesquisadores ao Nordeste e Norte do País em 1938, encarregada de registarem discos (12 rotações) ofolclore musical: foram coletados 689 objetos; tiradas 751 fotografias e 1.295 fonogramas, 
além de alguns filmes. Esse material foi gravado em 115 discos, acompanhados de livros sobre as temáticas sonoras coletadas - Xangô, Tambor-de-Mina e Tambor-de-Crioulo, Catimbó, Babassuê, Chegança de Marujos e Bumba-meu-boi. Foram editados dois volumes especiais da série Arquivo Folclórico: $1^{\circ}($...)Melodias Registadas por Meios NãoMecânicos (570 melodias); $2^{\circ}(. .$.$) CatálogoIlustrado doMuseufolclórico$ (275 fotos, notas explicativas, índices do material). “... Trata-se de um labor que completa a obra de Mário de Andrade e honra o Folclore brasileiro, através do esforço pertinaz de Oneyda Alvarenga que dirige a Discoteca Musical de São Paulo, com clara inteligência e segura orientação. Enquanto não se criar um órgão capaz, técnica e financeiramente, de efetivar olevantamento do nosso folclore, a pesquisa continuará precária, dependendo apenas de boa vontade e sofrendo a invasão constante do apressado amadorismo" " . Esse enaltecimento do trabalho de Mário de Andrade e de sua equipe, realizado em 1938, foi escrito por Renato Almeida em 1957, na sua obra Inteligência do folclore...

No campo musical, as divergências entre Mário de Andrade, Renato Almeida, Câmara Cascudo, Rossini Tavares de Lima, Barrozo Neto, Villa-Lobos, Camargo Guarnieri, Lorenzo Fernandez, Luciano Gallet, entre outros intelectuais de tendências integralistas, eram muito pontuais, sem nenhum confronto teórico-metodológico ou político, de uma natureza polêmica ou contundente. Por essa razão, os "erros" apontados por Mário de Andrade na marginália da primeira edição da História da música brasileira, de Renato Almeida (1926), restringiamse a "informações" incompletas ou análises muito "fechadas" em torno da "riqueza" singular da musicalidade do "povo brasileiro".

Para Mário de Andrade, o 7 de setembro de 1822 representou um golpe instaurado pelas elites contra o "povo". E, por esse motivo, o romantismo musical internalizado nas "falas" desse povo foi cercado pela elite intelectual, presa à imitação de "modelos europeus". Mário acreditava que o romantismo, preso a um "inconsciente coletivo", representava, nas décadas de 1820 e 30 , uma revolta contra o artificialismo das concepções estéticas das elites do Império. E, paradoxalmente, devido à criação de um Estado como uma figura de ficção, manteve-se o silêncio desse povo até o momento da implosão do projeto republicano 
e darwinista, defendido pelos intelectuais da Belle Époque carioca (1889-1914): “... o samba é a música do carnaval por excelência e no seu movimento voluptuoso e febril há toda a nossa alegria, vindo os motivos de melancolia encobertos sempre em sarcasmos que evitam a tristeza. Um cabedal enorme de folk-lore existe nos seus versos desordenados, onde muito verteu a sabedoria popular, deixando intacta a sensibilidade nativa. Agora que o espírito moderno, libertando a arte brasileira da imitação e do passadismo, procura integrá-la na terra, onde estão as fontes inspiradoras que a cultura universalizará, todos esse motivos ardentes do canto popular servirão para a grande construção de nossa arte" 5 .

Essa "revolta popular" no campo cultural, mantida no anonimato durante um século (1822-1922), conforme periodização e concepção teleológica da História defendida por Mário e Renato, deveria ser descoberta pelos músicos modernistas através de uma cruzada em prol do "resgate" dos mais diversos tipos de saberes populares. Por essa razão, o"novo" a ser incorporado pela vanguarda artística e nacionalista deveria partir de uma retomada das "lições do passado", internalizadas no inconsciente coletivo do "povo brasileiro".

A busca utópica do "som nacional" baseava-se numa concepção evolucionista da História, ou seja, o início ou o "marco zero" da construção do projeto modemista na música deveria iniciar-se nos anos 20. O compositor interessado nesse projeto era obrigado a "vencer" ou "galgar" uma série de etapas ou fases, até alcançar um "momento" histórico, caracterizado pelo surgimento deuma ArtePura, desinteressada e esteticamente livre, tendo como paradigma uma lição do "passado": o século XVIII europeu: “... assim, pois, o século XVIII é o período clássico da música. O que caracteriza o classicismo dele é ter atingido, como nenhum outro periodo antes dele, a Música Pura, isto é: a música que não tem outra significação mais do que ser música; que comove em alegria ou tristeza pela boniteza das formas, pela boniteza dos elementos sonoros, pela força dinamogênica, pela perfeição da técnica e equilíbrio do todo. Nos restauma verificação importante a fazer. O período clássico é o período mais fecundo em compositores admiráveis. Mesmo quando a gente se limita a estudar os compositores menores, espanta a riqueza excepcional de qualidades musicais desses autores. O século XVIII é um 
tempo em que todo o músico escrevia bem! ${ }^{6}$. Porém não é que tivesse maismúsicos bons nessa época que entreos polifonistas do quinhentismo ou os monistas do século XIX romântico. O que faz essa gente do século XVIII parecer mais numerosa e excepcional, é ter o classicismo equilibrado enfim o conceito estético da música com a realidade dos elementos sonoros e o efeito deles no organismo humano. Não são os homens do século mais geniais que os dos outros séculos. A música é que se tornara mais perfeita e obrigava os compositores a uma maior perfeição. Ao passo que os preconceitos e falsificações estéticas da música romântica diminuem o valor, irregularizam muito a produção musical do século XIX; os compositores menores do Romantismo nos parecem, quando não insuportáveis, no geral destituídos de interesse" ?

Era imprescindivel, portanto, criar uma Arte Pura brasileira, tendo como fonte de inspiração o folclore. Paradoxalmente, consoante Renato Almeida eMário de Andrade, oromantismo musical erauma "invenção" do povo brasileiro, antes de sua chegada oficial na literatura, em 1830. Os cantos folclóricos já denotavam um "irracionalismo impetuoso", opondo-se aos sistemas "fechados" e "racionais" do iluminismo francês. Os matizes românticos da cultura popular revelavam o caráter melancólico e "rebelde" do povo brasileiro. A tristeza, a melancolia, internalizadas no "povo", de acordo com Renato Almeida, harmonizavam-se com a natureza "exuberante" e "dominadora". Assim, "... a obra romântica, portanto, não era uma imitação do movimento europeu, mas um impulso do nosso espírito, o destino histórico que cumpríamos"s.

Para os modernistas, era fundamental retomar essas "falas" populares, "sufocadas" pela elite intelectual e política do Império e dos primeiros anos da República. Por que? O "fato" folclórico representava um documento histórico verdadeiro e inquestionável, sob o ponto de vista da interpretação artística. Competia ao intelectual modernista resgatar essa verdade: "... uma das manifestações mais características da música popular brasileira são as nossas danças dramáticas. Nisso o povo brasileiro evolucionou bem sobre as raças que nos originaram e as outras formações nacionais da América. Possuímos um grupo numeroso de bailados, todos eles providos de maior ou menor entrecho dramático, textos, músicasedanças próprias..." ". Deacordocomessa "interpretação" 
daHistória do Brasil, o romantismo, sob a óptica das camadas populares, não incidia num mimetismo dos "modelos" europeus (G. Verdi ou Wagner).

A transfiguração dessa ampla documentação folclórica a ser concretizada pelos compositores presos a uma Escola (sistematização de princípios técnico-estéticos), dar-se-ia somente com o surgimento de um rapsodo que reproduzisse o ritmo brasileiro como símbolo da conquista da terra. A partir dessa interpretação da História, Carlos Gomes (compositor do século XIX), devido ao "divórcio" entre elite e povo, acabou sendo "prejudicado" sob o ponto de vista estético, pois foi "obrigado" a "... desprezar as vozes da terra" ${ }^{10}$. De um lado, n'O Guarani de José de Alencar, era possível, conforme Renato Almeida, distinguir com nitideza diferença entre linguagens utilizadas pelosíndios e pelos brancos; de outro, n'O Guarani, ópera de Carlos Gomes, os cantos dos índios fundamentavam-se nas mesmas modulações do sistema tonal e das árias italianas, negando, assim, a própria História, ou seja, as músicas dos indígenas brasileiros que refletiam uma "liberdade audaciosa", símbolo das "nossas selvas".

Eo"povo" brasileiro eraformado, basicamente, pelos portugueses, africanos e ameríndios. É somente a partir dessas "três bases étnicas" que o "povo" vinha celebrando "... secularmente em suas danças dramáticas" ". Os chamados "fatos históricos oficiais" denossaHistória, conforme uma visão positivista de Mário de Andrade, nunca foram utilizados como "temas" nas mais diversas manifestações folclóricas no Brasil; “... nemastragédias da colonização que durou quase dois séculos, nem os dramas da catequese, nem a própria volúpia aventureira do bandeirismo (...) nem mesmo a Guerra do Paraguai que vincou fundo a memória coletiva e até agora freqüenta o nosso verso cantado: nenhuma dança dramática celebra esses feitos" ${ }^{12}$.

De acordo com essa concepção de memória e de História ${ }^{13}$, Mário de Andrade, Renato Almeida, Lorenzo Fernandez, Luciano Gallet definiram a vanguarda modernista e nacionalista na música como um resgate dos temas da cultura popular. Esses intelectuais almejavam, em síntese, criar uma Escola Nacionalista de composição, de natureza hegemônica, epropiciaruma ruptura da cultura brasileira erudita em face da "... subserviência da Europa" ${ }^{14}$ ou da "... perturbação das escolas 
estrangeiras" ${ }^{15}$. A ênfase atribuída à canção folclórica ${ }^{16}$ induziu-os a privilegiar a concepção do Brasil como uma "Nação" essencialmente ruralista. Paradoxalmente, esse imaginário envolveu intelectuais dos grandes centros urbanos - São Paulo e Rio de Janeiro - nas décadas de $30,40,50$ e 60, que participaram de cruzadas em prol da busca das "falas" do "homembomerústico" nos Estados de Goiás, Mato Grosso, Amazonas, Rio Grande do Norte, Paraíba, Pernambuco, Bahia, interior de São Paulo, Minas Gerais, entre outros.

Entretanto, sob o ponto de vista da memória histórica, na década de 1920, consoante Mário de Andrade, entre outros modernistas, não havia aflorado um grupo de compositores interessados pelo "nacional" e pelo "popular" na criação de uma Arte Culta: "... a nossa música não tem filiações no Brasil, não temos mestres, nem discípulos" 17 . Utopicamente, os modernistas admitiam que somente no momento do surgimento de uma Escola, os "... nossos músicos" tornar-se-iam mais "livres" e "desabusados", “... donos de sua arte, dominando as convenções e exaltando o som na prodigiosa sinfonia da terra" 18 .

Para Mário de Andrade e Renato Almeida, somente Heitor VillaLobos, durante os anos 20, já havia iniciado, em algumas obras, essa "independência cultural" do Brasil em facedos pólos musicais europeus: "... a riqueza dos seus ritmos, as dissonâncias, o colorido violento e caprichoso, a imagética fecunda, a ironia amarga e sardônica, um acento elegíaco queaparece sempre sob milformas, acentuam os característicos da alma brasileira, que freme nessa música, de uma idealidade inquieta ... [Além disso], Villa-Lobos procura universalizar o elemento básico da música, que é o canto popular, sem traí-lo, mas despertando o que nele há de humano (...). A sua música se pode chamar de brasileira, porque nela tudo marca o ambiente em que se cria, embora sob uma forte influência cultural. Quando julgamos que se deve fazer arte brasileira, isso na música, na pintura, na literatura, na escultura ena arquitetura, não pretendemos queo seu característico esteja somente no motivo brasileiro, mas em sentir como brasileiro" 19 .

Conforme a "periodização" da música brasileira proposta por Mário de Andrade (de 1500 a 1920), as obras dos compositores eram fundamentalmente "européias", mesmo entre os nacionalistas "... que se interessaram pela representação musical da coisa brasileira" 20 . 
A criação de um pólo musical no Brasil durante o após-guerra (1918) prendia-seà concepção spenceriana ou evolucionista da História. Para Mário de Andrade, num texto divulgado em 1939²1, a música no Brasil percorreu os seguintes "momentos":

$\left.1^{\circ}\right)^{66}$ Deus" (1500-1822.- peças musicais introduzidas no Brasil pelos jesuítas e utilizadas na catequização dos índios; sem nenhuma importância técnica ou estética, apenas cumpriam um objetivo social imposto pela Igreja;

2)"Amor" (1822-1918): o "golpe da independência" (7 de setembro de 1822), instaurado pela elite burguesa, contribuiu para o advento detemas profanos nas óperas, canções (modinhas, lundus). Esse "momento histórico" também foi caracterizado por Mário de Andrade como a fase do "internacionalismo musical", ou seja, obras escritas pelos compositores que procuravam imitar os "modelos" europeus: Liszt; Verdi ou Wagner;

$\left.3^{\circ}\right)^{66}$ Nacionalidade" (a partir de 1918): fase iniciada por $\mathrm{H}$. VillaLobos, no momento em que este compositor "abandonava consciente e sistematicamente o seu internacionalismo afrancesado" (22). Conforme Mário, de 1918 a 1939 surgiram compositores que procuravaminspirarse nos temas das culturas populares, como por exemplo: Luciano Gallet, Lorenzo Fernandez, Francisco Braga, Barrozo Neto, Francisco Mignone, Camargo Guarnieri, Frutuoso Viana, Radamés Gnatalli e H. VillaLobos. O programa em prol da nacionalização da música fundamentavase, em síntese, no princípio do "progresso" e da "evolução" da História: "... de todas as fases por que tem passado a música brasileira em sua evolução, a mais empolgante é sem dúvida esta contemporânea. Todas as outras foram mais ou menos inconscientes, movidas pelas forças desumanas e fatais da vida, ao passo que a atual, embora também necessária por ser um degrau evolutivo de cultura, tem a sua necessidade dirigida e torcida pela vontade, pelo raciocínio e pelas decisões humanas..." 23.

$\left.4^{\circ}\right)^{66}$ Fase cultural" ou utópica : "... o movimento modernista, eminentemente crítico por natureza, parecia implicar numa grande evolução ulterior de cultura, mas tal não se deu. Os novos não agüentaram o tranco. E o "despoliciamento intelectual" ${ }^{24}$ do país, de editores, jornais e revistas, especialmente, a camaradagem da crítica tão 
madrinha como comodista, permitiu esse estado assombroso de coisas, cujo menor defeito ainda é a superstição nacional do talento (...) Mas, a faltageral detécnica do compositorbrasileiroéprincipalmente determinada pela nossa situação econômica" 25 .

Esse "momento" do surgimento de um possível insight, verdadeiramente nacionalista, somente ocorreria numa "conjuntura histórica" muito específica: a) o compositor deveria dominar todos os conhecimentos técnico-estéticos da linguagem musical neoclássica e de umprogramaneo-romântico, sob omatiztemático;b) oartista abandonaria a pesquisa do folclore em prol da construção de um discurso sonoro comprometido como "cultural" ou "nacional", conformea utilização de uma morfologia sui generis; c) o afloramento de um forte "policiamento" de críticos "competentes" (profundos conhecedores da estética modernista no campo da música); de professores e intérpretes comprometidos com a Arte Pura e "nacionalmente desinteressada"; d) o "desaparecimento" deburocratas "medíocres"e "incompetentes", que através da camaradagem, do clientelismo e fisiologismo vinham promovendo uma série de artistas, totalmente "alienados", em face da criação de uma Escola Nacionalista de Composição.

Por esses motivos, Mário de Andrade, em algumas de suas críticas publicadasnosjornais, procuravaapontar os "descaminhos" de alguns compositores quevinham praticando "desvios", quepoderiam colocar em xeque o projeto modernista. À guisa de exemplificação, Mário de Andrade, em sua crítica a respeito da peça musical Toada de Camargo Guarnieri, em 7 de setembro de 1930, afirmava: “... e me parece incontestável que Camargo Guarnieri está se repetindo... criou pra seu uso pessoal uma linha melódica mole, bem gostosa, saída das toadas caipiras do centro do Brasil; sistematizou certos ritmos sincopados dos mais artisticamente simplórios que o Brasil fornece (...). E os seus processos são tanto mais perigosos que não contribuem para he daruma fisionomia musical perfeitamente característica (...). Porém écedo ainda pra ele repousar em si mesmo. Tanto mais que está repousando no vago, pois ainda não se achou. E si falo desta maneira é que porque Camargo Guarnieri tendo todas as esperanças, e o considero o artista mais importante da sua geração, aparecido até agora" ${ }^{26}$. Na realidade, a canção folclórica deveria ser antropofagicamente deglutida pelo 
compositor, evitando-se, assim, possíveis pastichos do "material" folclórico.

Em 1927, Mário de Andrade já alertava para a inexistência de estudos rigorosos (científicos) do folclore no Brasil: “... é uma ausência vergonhosa", de um lado, e, de outro, advertia que a simples fundamentação nos temas folclóricos nunca "transformaria" um artista num "ser brasileiro": "... um músico brasileiro que fizesse música estilizando documentos puramente brasílicos se tornaria exótico mesmo dentro do Brasil" 27.

Os modernistas, em linhas gerais, consideravam o "povo" como oúnico everdadeiro guardião da nacionalidade. Competia ao compositor redescobrir, cultural e musicalmente, as "falas populares", que haviam sido cerceadas e censuradas pelas elites a partir do 7 de setembro de 1822 . Entretanto, as experiências "isoladas" empreendidas por Alexandre Levy, Alberto Nepomuceno ou Emesto Nazareth na busca de inspiração nas canções folclóricas, inseridas esporadicamente em algumas de suas obras, não denotavam, conforme Mário de Andrade, um nacionalismo estético capaz de aglutinar todos os compositores em torno de uma doutrina hegemônica, calcada nas "falas" do "povo". Nos anos 20, apesar das tentativas de H. Villa-Lobos, Mário advertia sobre a ausência deuma possível passagem da canção popular cultivada pelos "rapsodos andantes", para a "eternização dum Homero que a genializasse".

Essas oscilações, vivenciadas pelos compositores brasileiros, entre a "descoberta" de uma arte internalizada no "povo" e a imitação de "esquemas" europeus, foram exlicitadas com nitidez por Renato Almeida, em 1926: “... O sr. Villa-Lobos faz da música, da sua música, uma interpretação do fenômeno brasileiro, nas suas vozes de exaltação e melancolia, de pavor e doçura. Não as quis interpretar, traduziu-as apenas e criou, porque o artista é um transfigurador..." 28.

Entretanto, os modernistas acreditavam na instauração de um projeto educacional, de natureza pragmática, capaz de favorecer o afloramento deuma cultura nacional emusical verdadeiramentebrasileiras: “... no entretanto, ainda não temos uma formação de cultura musical perfeita e a educação do nosso gosto não está aprimorado. Há a perturbação do estrangeirismo, que é um elemento de corrupção digno de nota, e as preocupações infecundas de escolas, que queremos 
transportar para o nosso meio, alheio a tais quisilias. Mas, através de todos os entraves, a música no Brasil se liberta, buscando harmonizar as vozes da terra, o ritmo criador e fecundo, com o influxo de cultura, para a criação de uma arte autônoma, que traduza todas as ânsias do espírito moderno brasileiro (....) quese deverá criar éainda um esforço formidável, mas qualquer que ele seja não desprezará o que fez o passado, e, muito menos, a agitação moderna buscando re-integrar a música nas origens da terra e ligá-la pela cultura ao espírito universal" (29).

Essa concepçãoutópica, de colorações conservadoras, baseava-se em teorias estéticas defendidas no "passado" pelos formalistas Hanslick, Combarieu - e numa memória, que pretendia transfigurar-se numa concepção unilateral e singular sobre a verdadeira $A$ História da Mísica Brasileira, tendo como paradigma o modernismo e na busca "delirante" do chamado "som nacional". Este último período da História, somente ocorreria com o surgimento de alguns "gênios" ou "seres sem pátria", simpatizantes de uma doutrina baseada numa determinada técnica e numa função social da arte.

Entretanto, nafase da nacionalização, conforme Mário de Andrade - anos 30 -, devido à inexistência desses "gênios" ou "heróis", “...um artista escrevendo (...) em texto alemão sobre assunto chinês, música da tal chamada de universal faz música brasileira e é músico brasileiro. Não é não. Por mais sublime que seja, não só a obra não é brasileira como é anti-nacional. E socialmente o autor dela deixa de nos interessar. Digo mais: por valiosa que a obra seja, devemos repudiá-la, que nem faz a Rússia com Strawinsky e Kandinsky. O periodo atual do Brasil, especialmente nas artes, é o da nacionalização (...) E si o artista faz parte dos 99 por cento dos artistas e reconhece que não é gênio, então é que deve mesmo fazer arte nacional (...) A falta de cultura nacional nos restringe a um regionalismo rengo que faz dó. E o que é pior: Essa ignorância ajudada por uma cultura internacional bêbeda e pela vaidade, nos dá um conceito do plágio e da imitação que é sentimentalidade pura (...) Todas estas constatações dolorosas me fazem matutar que será dificil ou pelo menos bem lerda a formação da escola musical brasileira. O lema do modernismo no Brasil foi Nada de escola! Coisaidiota. Como si o mal estivesse nas escolas e não nos discípulos (...) Por isso que o Brasileiro é por enquanto $11 \mathrm{~m}$ povo de qualidades episódicas e de defeitos 
permanentes" 30

N'O Ensaio sobre a música brasileira, Mário apresentava o seu manifesto programático e doutrinário sobre a construção do discurso musical a ser concretizado, futuramente, pelos compositores. Numa primeira fase, o "nacional" restringia-se à pesquisa do folclore, almejandose recuperar a "Nação" inconscientemente internalizada no "povo". Sob esse matiz, Mário resgatava o folclore como uma sobrevivência do primitivo. Este, durante a primeira fase do modernismo musical, representava uma função social e não estética. Sob esse ângulo, Mário explicitava sua divergência em face das idéias de Oswald de Andrade, esboçadas no Manifesto do Pau-Brasil. O autor d'O Banquete criticava o lirismo oswaldiano como o símbolo de uma "brincadeira desabusada". "(...) A deformação empregada pelo paulista não ritualiza nada, só destrói pelo ridículo. Nas idéias que expõe não tem idealismo nenhum. Não tem magia. Não se confunde com a prática. É arte desinteressada. Pois toda arte socialmente primitiva que nem a nossa, é arte social, tribal, religiosa, comemorativa. É arte de circunstância. É interessada. Toda arte exclusivamente artística e desinteressante não tem cabimento numa fase de construção. É intrinsecamente individualista (...) O critério atual da Música Brasileira deve ser não filosófico mas social. Deve ser um critério de combate..." 31 .

Implicitamente, a recuperação da cultura popular como fonte de reflexão do artista enudito na busca da criação de uma Arte Nacional, significava uma profunda crítica às elites intelectuais da Belle Époque (Olavo Bilac, Rui Barbosa, Oscar Guanabarino, Coelho Netto). Nas duas primeiras décadas do século $\mathrm{XX}$, através de uma reurbanização da cidade do Rio de Janeiro e do ideal darwinista, uma facção da elite republicana e intelectual elegeu Paris como a capital da modernidade. $\mathrm{E}$, paralelamente, procurava adaptar à nossa realidade social, posturas decolorações racistas, antidemocráticas ealtamente preconceituosas em face das culturas populares, vistas como o símbolo da "barbárie", do atraso, da tradição. Por essa razão, os donos do poder reprimiram, com violência, através deforças policiais, as capoeiras, os batuques de negros, os participantes do bumba-meu-boi.

A construção da Avenida Central, por exemplo, significava para os simpatizantes de Pereira Passos, “ ... a fantasia de Civilização (...) Pois, 
as reformas, caso indicassem que os cariocas estavam a caminho da civilização pelo atalho da europeização, também significavam necessariamente uma negação, o final de muito o que era efetivamente brasileiro $^{32}$. Abraçar a Civilização significava deixar para trás aquilo que muitos na elite carioca viam como um passado colonial atrasado, e condenar os aspectos raciais e culturais da realidade carioca que a elite associava àquele passado" 33 .

Entretanto, apesar dessa ideologia do "progresso", os bilontras ou agente sociais dominados da cidade do Rio de Janeiro, entregavamseàs mais diversasmanifestações culturais: grupos dechorões; dançarinos de maxixes; batuques praticados nos fundos da Casa da Tia Ciata; festas religiosas da Penha e da Glória; os entrudos; os ranchos carnavalescos. Subterraneamente, foram surgindo, com intensidade, manifestações ligadas à música popular, projetando os nomes dePixinguinha, Anacleto de Medeiros; Donga; Ernesto Nazareth; Chiquinha Gonzaga...

Paradoxalmente, osmodernistas consideravamascançõesurbanas como o símbolo do "popularesco", devido a um intenso diálogo internacional entre jazz/choro/ragtime, que negava a "pureza" do folclore como paradigma de uma verdade histórica. "Brasil rural". O sucesso da tournée de Pixinguinha no cabaré Scherazade em Paris (1922), durante seis meses (momento em que passou a tocar saxofone, sob a influência do jazz); da gravação do seu chorinho "Urubu" em Buenos Aires (fins de 1922); o afloramento de centenas de músicas gravadas; o surgimento dos artistas do rádio, durante os anos 30, significaram para os modemistas a negação do "nacional" e do "popular" na música brasileira.

Osolhares eos ouvidos dos modernistas resgataramalgumas peças de Ernesto Nazareth, Chiquinha Gonzaga, Pixinguinha, Noel Rosa, somente nos trechos (temáticos e técnicos) passíveis de serem "aproveitados" pelo artista culto ou erudito. No entanto, esse novo tipo de preconceito - Arte Culta versus música popularesca (oriunda dos grandes centros urbanos.- implica uma pesquisa a ser concretizada futuramente. 


\section{Notas}

1. Mário de ANDRADE. O Ensaio sobre a música brasileira. São Paulo, L. Martins Editora, 1962.

Chiarato, 1929.

Martins Editora, 1975.

Compêndio sobre a música brasileira. São Paulo,

Aspectos da música brasileira. 2a. ed., São Paulo, L.

O Banquete. São Paulo, Duas Cidades, 1977.

Pequena história da música. 5a. ed., São Paulo, L.

Martins Editora, 1958.

. Macunaíma. São Paulo, L. Martins Editora, 1962.

"Prefácio Interessantíssimo". In: Paulicéia Desvai-

rada. 6a. ed., São Paulo, L. Martins Editora, 1980, pp. 193-275.

"A escrava que não é Isaura". In: Obra imatura. 3 a.

ed., São Paulo, L. Martins Editora/Itatiaia, 1980, pp. 52-64.

2. Apud Peter BURKE, Cultura popular na Idade Moderna. São Paulo, Companhia das Letras, 1989, p. 32.

3. Renato ALMEIDA, Inteligência do folclore. Rio de Janeiro, Livros de Portugal, 1957, p. 233.

4. Id., Loc. cit.

5. Idem, História da música brasileira. Rio de Janeiro, Briguiet, 1926, pp. 5455.

6. Grifo nosso.

7. Mário de ANDRADE, Pequena história da música. Op. cit., p. 111.

8. Renato ALMEIDA, História da música brasileira. Op. cit., p. 82.

9. Mário de ANDRADE, Danças dramáticas do Brasil. 2a. ed., Belo Horizonte, Itatiaia, 1982, (1):23.

10. Renato ALMEIDA, História da música brasileira. Op. cit., p. 87.

11. Mário de ANDRADE, Danças dramáticas do Brasil. Op. cit., p. 23.

12. Idem, Loc. cit.

13. "... A memória histórica filtra, acumula, capitaliza e transmite, a memória coletiva conserva por um momento a recordação de uma experiência intransmissível, apaga e recompõe a seu gosto, em função das necessidades do momento, das leis do imaginário e do retorno dos recalcamentos." $\mathrm{Na}$ realidade, a concepção de Mário de Andrade sobre a História incide numa concepção de "memória coletiva", conforme análises realizadas por Pierre Nora em seu artigo "Memória coletiva". In: A nova história. Coimbra, L. Almedina, 1990, pp. 451-4.

14. Mário de ANDRADE, Pequena história da música. Op. cit., p. 162.

15. Renato ALMEIDA, História da música brasileira. Op. cit., p. 122. 
16. O conceito de "música" defendido pelos modernistas e pelos folcloristas no período de 1920 a 60 (Mário de Andrade, Luciano Gallet, Câmara Cascudo, Renato Almeida, Rossini Tavares de Lima) restringiu-se a três níveis: $\left.1^{0}\right)$ música popular ou folclórica: transmitida oralmente numa determinada "evolução histórica" e inserida no âmbito de uma comunidade social específica; $2^{\circ}$ ) música popularesca: expressão sempre empregada conforme um sentido pejorativo, negativo. A canção urbana era considerada "suspeita" pelos folcloristas, devidoà sua inserção no binômio mercado / consumo; $3^{\circ}$ ) música erudita: símbolo da chamada arte culta ou "séria", praticada somente por artistas considerados profundos conhecedores da técnica de composição.

17. Renato ALMEIDA, História da música brasileira. Op. cit., p. 123.

18. Idem, ibidem, p. 160.

19. Idem, ibidem, pp. 170-171.

20. Mário de ANDRADE, Pequena história da música. Op. cit., p. 162.

21. Idem, "Evolução social da música brasileira". In: Aspectos da música brasileira. Op. cit.

22. Idem, ibidem, p. 32.

23. Idem, ibidem, p. 33.

24. Grifo nosso.

25. Mário de ANDRADE, "Evolução social...". Op. cit., p. 35.

26. Idem, "Compositores paulistas". In: Diário Nacional. São Paulo, 7/9/ 1930, p. 7.

27. Idem, "Canções brasileiras". In: Diário Nacional. São Paulo, 22/12/1927.

28. Renato ALMEIDA, História da música brasileira. Op. cit., pp. 173-174. Grifo nosso.

29. Idem, ibidem, pp. 220-221.

30. Mário de ANDRADE, O ensaio sobre a música brasileira. Op. cit., pp. 17 19; 70-72. Grifo nosso.

31. Idem, ibidem, pp. 18-19.

32. Grifo nosso.

33. Jeffrey NEEDEL, Belle Époque Tropical. São Paulo, Companhia das Letras, 1993, p. 70.

Arnaldo Contier, historiador e musicólogo, Professor associado Departamento História da FFLCH-USP 